\title{
LA WEB 2.0 EN MUSEOS ONLINE DE ARTE CONTEMPORÁNEO
}

José Nicolás del Río-Castro1: Universidade da Coruña. España jdelrio@udc.es

\section{RESUMEN}

Este artículo analiza los usos preferentes de la Web 2.0 en noventa y un museos online de arte contemporáneo. Los datos recogidos permiten establecer tres tipos de comunicación, dependiendo del formato 2.0 y del grado de implicación de los visitantes. La primera tiene como base los repositorios audiovisuales y blogs, y la segunda las redes sociales. Aunque son las más extendidas, la participación de los usuarios en ambos casos se reduce a valorar y comentar la oferta del museo. En consecuencia, las contribuciones de los visitantes discurren en paralelo a la comunicación institucional sin interferir en ella. El tercer tipo de relación se basa en foros, wikis, mash-ups, y etiquetado social, un conjunto de formatos que depende en gran medida de las contribuciones de los visi- tantes para funcionar; sin embargo su implantación es ínfima y apenas tiene repercu- sión. A juzgar por los datos recogidos, la relación de proximidad entre museo y visitantes que favorecen las tecnologías 2.0 es utilizada por la mayor parte de museos online de arte contemporáneo para difundir proyectos museográficos, más que para implicar al público en la co-creación de éstos.

PALABRAS CLAVE: Museos Online - Museos Virtuales - Web 2.0 - Internet - Arte Contemporáneo

\footnotetext{
${ }^{1}$ Autor correspondiente

José Nicolás del Río-Castro: Universidade da Coruña. España

Correo: jdelrio@udc.es
} 


\title{
WEB 2.0 IN ONLINE MUSEUMS OF CONTEMPORARY ART
}

\begin{abstract}
This paper analyzes the main uses of Web 2.0 in ninety-one online museums of contemporary art. From the collected data three types of communication can be established, depending on content format and audience involvement. The first one relies on audiovisual repositories and blogs, and the second one on so-cial networks. Both are the most widespread; however audience participation within these formats is limited to reviewing and rating some of the museum's online offer- ings. Consequently, visitors' contributions run parallel to the museum's institutional communication and do not interfere with it. The third type of relationship is based on forums, wikis, mash-ups, and social tagging; a group of formats which depend heavily on visitors' contributions for them to work; however their presence is mi- nimal and its repercussion practically non-existent. Judging from the collected data, the close relationship between museums and visitors brought about by 2.0 technologies is most often used by online contemporary art mu- seums to communicate museographic projects to their visitors, rather than involving them in the co-creation of those.
\end{abstract}

KEY WORDS: Online museums - virtual museums - Web 2.0 - Internet contemporary art

\section{INTRODUCCIÓN}

En pocos años, la implantación generalizada de la Web 2.0 ha transformado la Red en un espacio de participación, colaboración e intercambio. Su aceptación ha crecido hasta tal punto que en Inglaterra las redes sociales se han convertido en la actividad más popular de Internet (Barnett, 2011). Empresas, instituciones y organizaciones son conscientes de la relevancia que los usuarios otorgan a su participación online. Por ello, han buscado formas de incorporar los formatos 2.0 a sus propios websites $\mathrm{y}$, al mismo tiempo, expandir su presencia a redes sociales y repositorios de contenidos audiovisuales donde la oferta del museo está expuesta a un volumen excepcional de visitantes.

Por ejemplo, los 600 millones de usuarios de Facebook, se conectan un promedio de 40 veces al mes durante 23 minutos mientras que los 490 millones de usuarios de YouTube hacen visitas de 25 minutos, 14 días al mes. ${ }^{2}$ Aunque los museos no han sido ajenos a la adopción generalizada de la Web 2.0, esta tendencia no se encuentra demasiado extendida entre las instituciones europeas (López, Margapori, Maragliano \& Bove, 2010, p. 235).

\footnotetext{
${ }^{2}$ royal.pingdom.com/2011/02/04/facebook-youtube-our-collective-time-sinks-stats. (Consultado el 19/6/2011)
} 
La escasa implantación en Europa tiene una única excepción en Inglaterra cuyas cifras resultan próximas a las de EE.UU. En el caso de websites de museos que cuentan con blogs, Italia tiene 0\%, España 2,1\% y Francia 4,2\%, mientras que Inglaterra alcanza un 10,4\% y Estados Unidos un 16,7\% (López et al., 2010, p. 244). ${ }^{3}$ Estos datos sugieren que la política online de la mayoría de museos apenas tiene en cuenta la participación de la audiencia. En consecuencia, la oferta de los museos online se centra principalmente en la transmisión de contenidos institucionales, sin tener en cuenta "conocimientos no-expertos" (López et al., 2010, p. 246).

Este modelo de difusión perpetúa en gran medida esquemas tradicionales en los que "la voz in-cuestionable" de la institución (Walsh, 1997) se dirige a "recipientes vacíos" (Marsh, 1996). Por el contrario, la Web 2.0 propone un espacio de comunicación compartido, aunque esta coyuntura resulta difícil de calibrar para los museos, ya que implica aceptar las voces no profesionales de los visitantes dentro del espacio institucional.

\section{DESARROLLO}

\subsection{La relevancia de la Web 2.0 para los museos}

El término Web 2.0 se atribuye a Tim O’Reilly (2005) quien inicialmente acuñó esta denominación para identificar un conjunto de tecnologías que pudiesen servir como indicadores de empresas y mercados innovadores. ${ }^{4}$ En un artículo posterior $\mathrm{O}^{\prime}$ Reilly (2009) revisaba su percepción inicial y señalaba que el verdadero valor de la Web 2.0, más que residir en la propia tecnología, radica en la capacidad de ésta para permitir la co-creación de contenidos online por y para los usuarios. En sus propias palabras, "la Web 2.0 consiste en canalizar la inteligencia colectiva" (O'Reilly, 2009, p.1).

En un artículo ampliamente reconocido, Anderson (Anderson, 2007, p. 14-26) incide en que la forma más adecuada de entender la Web 2.0 consiste en diferenciar entre las tecno- logías online y las "grandes ideas" surgidas a partir de ellas. Para Anderson las prime- ras no son más que una fase del desarrollo constante de la Web, 5 mientras que las se- gundas son "algo con un enfoque social mucho mayor" (Anderson, 2007, p. 4). Anderson identifica seis grandes ideas que conforman y dan carácter a la Web 2.0: producción individual y contenidos generados por los usuarios, la capacidad de la multitud, da- tos a una escala épica, arquitectura de participación, efectos de la Red 6 y estándares abiertos.

\footnotetext{
${ }^{3}$ Los datos se recogieron entre marzo y mayo de 2008 por lo que presumiblemente un recuento actual modifique estos valores al alza. El sondeo fue realizado sobre 240 museos de España, Francia, Inglaterra, Italia y Estados Unidos.

${ }^{4}$ El título completo del artículo revela esta perspectiva comercial: “¿Qué es la Web 2.0? Patrones de diseño y modelos de negocio para software de nueva generación."

${ }^{5}$ A saber: blogs, wikis, etiquetas y marcadores sociales, repositorios para compartir archivos multimedia, podcasts, RSS y nuevos servicios 2.0 (redes sociales, mash-ups, etc.).

${ }^{6}$ Se refiere a dos aspectos: Network Effect (un producto resulta más valioso cuantos más usuarios lo utilicen) v Lone Tail (un pro- ducto poco demandado resulta rentable a largo plazo).
} 
Sin detenernos en las especificidades de cada una de estas ideas, su relevancia conjunta gira en torno a la posibilidad de acceder al vasto universo de los datos online no sólo para la consulta sino también para su uso. Este viraje marcó un cambio de perspectiva; si la Web 1.0 se había caracterizado por ser una red de documentos enlazados, la Web 2.0 se definía como una red de usuarios interconectados. El rasgo de valor añadido es que este nuevo modelo convierte "a millones de Internautas en potenciales editores. Además, ofrece la oportunidad de explotar la inteligencia colectiva de estos internautas" (Espadas 2009, p. 2).

Aplicar la perspectiva social de la Web 2.0 a los museos online significa potenciar un museo participativo que proporcione un mayor acercamiento entre entidad y visitantes. Desde este punto de vista, Internet refuerza un cometido fundamental del museo: ser relevante para la sociedad en la que se integra. La Web 2.0 permite a los museos construir comunidad, fidelizar a los visitantes, entablar diálogo con ellos y llegar a públicos diferentes de los habituales (Rodá, 2010, p. 24).

Para los profesionales de museos que aprecian estos valores y consideran la Web 2.0 más que una oportunidad de utilizar una tecnología de moda, el uso de los medios sociales impulsa la museología online hacia tres objetivos interrelacionados: una institución centrada en los visitantes, la opción de que los visitantes construyan sus propios significados y la posibilidad de que las voces de los usuarios puedan dinamizar tanto el diseño de proyectos como los programas orientados al público (Simon, 2010, p. ii). Bajo este plantea- miento, el museo deja de ser sólo una autoridad que facilita información; se transforma en una plataforma de conocimientos y herramientas para que los visitantes exploren sus propias ideas y lleguen a sus propias conclusiones (Kelly 2009).

Aunque los museos son conscientes de la repercusión y alcance de la Web 2.0, su implantación en museos se ve ralentizada por reticencias de diversa índole. Para algunas instituciones implica una degradación del discurso profesional que se "diluye deliberadamente con los aportes sustanciales de los usuarios" (MacArthur, 2007). Para otras, podría degradar la apreciación de los museos físicos, reduciendo su amplia labor a la acumulación de obras, y presentándolos únicamente como "anticuados agrupadores de contenido fuera de línea" (Flatt 2010, p. 36-37).

A estas dos percepciones de carácter global le acompaña una serie de condicionantes internos: afrontar cambios organizativos internos (Rodá, 2010, p. 24-25), actitudes de rechazo ante tecnologías intrusivas (Peacock, 2008, p. 333-351), recelos ante las limitaciones de uso que imponen los de- rechos de reproducción o aversión a involucrarse en espacios "poco serios" como Facebook (Vogelsang \& Zinder, 2011). Adoptar la Web 2.0 implica para los museos compartir en cierto grado el control de la información. Mientras que para algunas instituciones resulta una parte fundamental de su esfuerzo por ser relevante para el público, otras debaten qué mecanismos utilizar para que las contribuciones de los visitantes contaminen lo menos posible la comunicación del museo. 
Ambas perspectivas esconden planteamientos y percepciones divergentes con respecto al valor y la fun- ción de los museos online. En este punto resulta revelador traer a colación uno de los primeros estudios sobre la clasificación de los museos en la Red. En 1999 Teather y Wilhelm proponían diferenciar entre museos online orientados a los objetos y la información, y museos online dirigidos a la gente y el significado. Los primeros se centran en las colecciones y la investigación, y su objetivo consiste en "difundir información al público e incrementar el nivel de conocimientos dentro de la institución". El segundo modelo refleja "las experien-cias individuales y de construcción de significado de los visitantes [...] y el fomento de múlti-ples voces". No resulta difícil predecir qué tipo de museo sería el más receptivo a in-corporar los formatos de la Web 2.0.

\subsection{La Web 2.0 en museos de arte contemporáneo}

Para analizar los diversos formatos de la Web 2.0 sumaremos las tecnologías citadas por Anderson (Anderson, 2007) y las recogidas por Espadas (Espadas, 2009). El conjunto de ambas pro- puestas ofrece un listado exhaustivo de los recursos participativos y colaborativos que engloba la Web 2.0: repositorios para compartir vídeos, audios, fotografías, mar- cadores y presentaciones, blogs, microblogs, redes sociales, RSS, foros, wikis, mash- ups y etiquetado social. Sin embargo, antes de analizar los datos recopilados, resulta esclarecedor dividir este conjunto de herramientas online en tres categorías según el grado de implicación de los visitantes.

En primer lugar se encuentran los repositorios externos al website institucional. Son espacios abiertos a cualquier usuario que funcionan como bibliotecas compartidas de materiales audiovisuales. Cada uno de ellos se centra en un medio específico: ${ }^{7}$ vídeos (YouTube, Vimeo, Blip.tv, DailyMotion, etc.), fotos (Flickr, Picasa, etc.), audios (Itunes), presentaciones (SlideShare) y marcadores de sitios web (Delicious, Digg, Google Buzz, etc.). En estos espacios los contenidos producidos por el museo tienen igual relevancia que las creaciones de cualquier otro usuario. Se trata de un modelo democratizador que iguala a profesionales y aficionados.

En este primer grupo de tecnologías también tienen cabida los blogs, cuyo formato preferente de difusión es el texto, aunque, a diferencia de los anteriores, están normalmente alojados en la web del museo.

Un segundo grupo está integrado por las Redes Sociales (Facebook, MySpace, Tuenti ${ }^{7}$ ) entre las que también se incluyen microblogs (Twitter, Tumblr) que funcionan formando grupos de seguidores en torno a una persona, una institución u organización, o un tema. La razón de ser de ambos formatos consiste en conectar a usuarios con gustos afines para formar grupos de interés, de manera que la información circule y se comparta entre sus integrantes. Similares a este modelo son los canales RSS, que

\footnotetext{
${ }^{7}$ Algunos repositorios pueden incorporar varios formatos, por ejemplo, Flickr no sólo admite fotos sino también vídeos.
} 
envían notificaciones a usuarios particulares sobre las actualizaciones de los websites a los que previamente se habían suscrito.

El tercer grupo engloba los formatos cuyo funcionamiento depende en gran medida de la implicación de los visitantes: foros, wikis, mash-ups y etiquetado social. Son recursos habitualmente ubicados en la propia web del museo que requieren visitas continuadas para ampliar las contribuciones, editar las de otros participantes o crear otras nuevas. El sondeo de estas tecnologías en 91 museos de arte contemporáneo de todo el mundo (ver listado en el la sección Webgrafía), ofrece los resultados que figuran en la Tabla 1.

Un análisis general de los datos nos permite constatar la gran popularidad de las redes sociales, ya que los porcentajes más altos pertenecen a este grupo. El porcentaje más alto $(76.9 \%)$ corresponde en su práctica totalidad a Facebook puesto que la presencia de otras redes sociales es muy escasa (MySpace aparece en 6 museos, un $6,6 \%$ ) o anecdótica (Tuenti sólo figura en un museo).

Los microblogs se encuentran el segundo puesto en popularidad (63.73\%) y se reducen prácticamente a Twitter (Tumblr aparece como alternativa en un solo museo). Los blogs $(43,95 \%)$ y los repositorios para compartir vídeo $(42,85 \%)$ son los segundos formatos más populares. En tercer lugar se encuentran los repositorios para compartir contenidos audiovisuales. Entre ellos destaca YouTube, que es el espacio preferente para compartir vídeos en 33 museos. Con un impacto mucho menor se encuentran Blip.tv, que figura en tres, Vimeo y Art. Babble, presentes en dos y DailyMontion en uno. 
Tabla 1. Formatos 2.0 en 91 museos online de arte contemporáneo. Fuente: elaboración propia.

Formatos Web 2.0

$\mathrm{N}^{\mathrm{o}}$ museos Presencia

\begin{tabular}{lrr}
\hline & $42,9 \%$ \\
\hline Repositorios compartidos de Fotografía & 33 & $36,3 \%$ \\
\hline Repositorios compartidos de Audio & 23 & $25,3 \%$ \\
\hline Repositorios compartidos de Presentaciones & 1 & $1,1 \%$ \\
\hline Blogs & 40 & $43,9 \%$
\end{tabular}

\begin{tabular}{lrr}
\hline & & $76,9 \%$ \\
\hline Micro Blogs & 58 & $63,7 \%$ \\
\hline RSS & 36 & $39,6 \%$
\end{tabular}

\begin{tabular}{lrr}
\hline & & $2,1 \%$ \\
\hline Wikis & 1 & $1,1 \%$ \\
\hline Mash-Ups & 1 & $1,1 \%$ \\
\hline Etiquetado social & 1 & $1,1 \%$ \\
\hline
\end{tabular}

La popularidad de los repositorios de fotografía y audio muestra una polarización similar, al ceñirse básicamente a una única web. En el caso de fotografías se trata de Flickr (un solo museo ha elegido Picasa como alternativa) y en el de audio, iTunes; éste sin competencia. Los repositorios de presentaciones son los únicos espacios de materiales compartidos que tienen una única incidencia. En último lugar, y con datos extremadamente bajos (entre un $1,1 \%$ y un $2,1 \%$ ), se encuentran foros, wikis, mashups y etiquetado social.

Resulta curioso comprobar cómo las tecnologías con la implantación más baja (con la excepción de los repositorios de presentaciones) son las que ofrecen el mayor grado de colaboración de los usuarios para aportar contenidos propios y crear recursos compartidos. A partir de los datos recogidos podemos establecer tres tipos de relaciones entre el museo y sus visitantes. Cada una de ellas impone al público un grado diferente de implicación.

\subsection{De uno a muchos}

Son los contenidos que hemos incluido en el primer grupo de tecnologías (repositorios para compartir contenidos audiovisuales y blogs). Los contenidos que oferta el museo en los repositorios se caracterizan por ser cerrados, creados tal cual para su difusión y sin posibilidad de modificación por parte de los visitantes. 
Se trata, por ejemplo, de un vídeo del comisario de una exposición entrevistando a un artista, de una selección de fotografías que documenta el montaje de una instalación o de una nota en un blog que informa sobre una conferencia.

En este discurso unidireccional del museo hacia los visitantes las opciones de participación de los usuarios se reducen a opinar y a valorar positiva o negativamente un contenido. A pesar de todo, y gracias a la creatividad e iniciativa de algunos visitantes, estos formatos inicialmente cerrados han llegado a abrirse a las aportaciones del público. Posiblemente el caso más popular sea el del colectivo de estudiantes ArtMobs (mod.blogs.com/art_mobs) que en 2004 crearon versiones alternativas a las audioguías oficiales del MoMA y las colgaron en la Red. Se trataba de locuciones que utilizaban canciones y composiciones sonoras como ambientación para la visualización de las obras, aportando comentarios cómicos o críticos e incluso entremezclando historias personales.

Por ejemplo, durante la descripción de Family Picture de Max Beckman se oye una canción de hip-hop mientras que en el audio correspondiente a Echo Number 25 de Pollock se puede oír un sarcástico debate entre un profesor y dos alumnas que proponen una lectura sexual de la obra. Tras la popularidad de esta iniciativa, el MoMA invitó a sus visitantes a elaborar sus propias locuciones y a enviarlas al museo para agregarlas a las oficiales, entendiendo que habría siempre un filtrado previo.

La entidad aún mantiene viva esta iniciativa (www.moma.org/visit/plan/atthemuseum/createyourown) y ofrece sugerencias sobre cómo elaborar audioguías personales. A diferencia del audio, las fotografías son menos flexibles para este tipo de prácticas debido a las limitaciones que imponen los derechos de reproducción. No obstante, hay excepciones. Mientras que la mayoría de museos sólo utiliza los repositorios de fotografía para publicar imágenes tomadas por la entidad, el Stedelijk holandés propone a los visitantes que "compartan sus fotos con nosotros en Facebook, Flickr o Twitter" (journal.stedelijk.nl/2011/04/fotosstedelijk-museum).

El MART italiano también apoya este tipo de iniciativa aunque, consciente de los derechos de reproducción, advierte que antes de tomar fotos en el museo se compruebe la posibilidad de hacerlas ya que los únicos usos permitidos se restringen al ámbito privado, a los medios de comunicación y a fines educativos (flickr.com/groups/mart).

Las limitaciones de copyright afectan igualmente a los vídeos pero a diferencia de audios e imágenes, ningún museo anima a sus visitantes a aportar creaciones videográficas. En el caso de los blogs, los derechos de reproducción resultan, a priori, poco relevantes ya que se nutren principalmente de aportaciones personales de texto, aunque pueden incluir recursos adicionales como fotografías, audios, vídeos o enlaces a otros contenidos de la Red. 


\subsection{De uno a uno}

Los contenidos del segundo grupo, redes sociales y microblogs, son los formatos 2.0 más extendidos. Prácticamente tres de cada cuatro museos analizados tienen presencia en Facebook y casi dos tercios de ellos tienen una cuenta en Twitter. Su finalidad principal es fidelizar a la audiencia entablando un trato más cercano con sus usuarios. El museo, en vez de colgar información sólo en su web institucional o en webs externas (como las descritas en el primer grupo), envía información directa a todos los visitantes que voluntariamente se han integrado en su canal social. De este modo la entidad tiene la certeza de que la información ha llegado a sus destinatarios y que su difusión no depende de otros medios de comunicación.

La ventaja de las redes sociales es que la relación "uno a uno" tiene un efecto multiplicador ya que potencialmente se extiende a la red de amistades de cada usuario y ayuda a expandir la información. En este contexto la participación de los visitantes se limita a reacciones mínimas sobre las notificaciones del museo, sin opciones para la creación de contenidos compartidos.

En los formatos descritos en los dos grupos anteriores (repositorios y blogs, y redes sociales) la contribución del público está limitada a valoraciones y comentarios sobre la propuesta del museo. ${ }^{8}$ La opción de réplica que ejercen los visitantes hace que se creen pequeñas conversaciones entre el público y la entidad o entre los propios visitantes. Sin embargo, el hecho de permitir únicamente pequeños espacios de opinión puede entenderse como un mecanismo de auto-defensa de los museos ya que las aportaciones de los visitantes "suponen en último término una injerencia en el control de la información" (Crenn \& Vidal, 2008). A pesar de ello, un grupo reducido de los museos analizados utiliza formatos 2.0 en los que la colaboración del público en proyectos compartidos no supone un obstáculo sino un beneficio.

\subsection{Entre todos}

El tercer y último grupo de tecnologías 2.0 está formado por foros, wikis, mash-ups y etiquetado social. En conjunto, su presencia en museos de arte contemporáneo resulta anecdótica ya que de los 91 museos analizados sólo están presentes en dos (foros) o uno (wikis, mash-ups y etiquetado social).

Los foros tienen un gran potencial para desarrollar propuestas centradas en el debate e intercambio de opinión. Aunque son formatos de gran popularidad en deportes, televisión o entretenimiento, prácticamente no existen en museos de arte contemporáneo. Aunque el foro del Patio Herreriano está accesible, (www.exploradorarte.com/exploradorArte/ComunidadArte) su última contribución data de enero de 2008.

\footnotetext{
${ }^{8}$ Funcionalmente se asemejan a los tradicionales libros de visita en los que el público registra sus impresiones personales.
} 
El Guggenheim de Nueva York, en cambio, es el único que permanece en activo (www.guggenheim.org/new-york/interact/online-forum), quizás porque propone un formato diferenciado en el que se identifica a un moderador y a varios ponentes que exponen sus puntos de vista. A partir de ellos se incorporan los comentarios de los visitantes.

Las wikis se reducen a dos sucursales del Guggenheim, Nueva York y Bilbao, y en ambos casos están dirigidas a un sector específico de público: el profesorado. El museo de Bilbao denomina esta herramienta Wikidocentes.

En este proyecto_(www.guggenheim-bilbao.es/wikidocentes/index.php/Portada) el museo cede el testigo del control de la información a "la experiencia de profesionales experimentados" para asegurarse que las contribuciones de los usuarios cumplen con unas garantías mínimas de calidad. El Guggenheim de Nueva York, dispone una iniciativa similar aunque no expresamente reconocida como wiki. Bajo el título Learning through Art (www.guggenheim.org/new-york/education/schooleducator-programs/learning- through-art) invita a la aportación de unidades didácticas a una base de datos online de libre acceso y organizada por tema, curso escolar, asignatura, técnica artística, etc.

Los mash-ups son herramientas que permiten a los usuarios elaborar contenidos nuevos a partir de una variedad de recursos disponibles en la web del museo. Por ejemplo, a un nivel básico pueden considerarse mash-ups las galerías personalizadas de imágenes de la colección. Instituciones como el museo Whitney o la Tate Online ofrecen la posibilidad de seleccionar imágenes de sus colecciones y reorganizarlas en nuevos conjuntos que resulten más significativos a nivel personal.

Más relevante aún, resulta la propuesta del Walker Art Center en colaboración con el Minneapolis Institute of Arts (www.artsconnected.org). Ambos museos ponen a disposición de los visitantes un archivo online de más de 100.000 fondos artísticos y documentales para su reelaboración en presentaciones. Cada presentación se identifica con el nombre y categoría de su creador (trabajador del museo, docente, estudiante...), permite incorporar comentarios de otros visitantes $y$, una vez finalizada, queda disponible en un repositorio público.

Por último, el etiquetado social es una herramienta de clasificación colectiva que permite a los visitantes redefinir los fondos online del museo con sus propias palabras. Por ejemplo, la pieza de Giacomo Balla Puño de Bocionni - Líneas de fuerza II de la colección del Museo Hirshhorn se presenta acompañada de una breve ficha técnica en la que figuran las categorías habituales de fecha, artista, material, tamaño, etc. (hirshhorn.org/visit/collection_object.asp?key=32\&subkey=3692). 
Sin embargo, el significado que los visitantes han otorgado a la obra está presente en etiquetas adicionales aportadas por ellos mismos: rojo, puntiagudo, afilado, soviético, futuro, equilibrio, confusión, explosión, acción, etc. Todas ellas son palabras que no forman parte de la catalogación museográfica tradicional sino que pertenecen al lenguaje cotidiano.

Se trata de referencias que resultan más relevantes para un público no experto y que, al funcionar como enlaces, permiten buscar otras obras que han sido descritas con alguna de esas etiquetas. El etiquetado social permite redefinir los fondos del museo desde una perspectiva alternativa a la profesional sin eliminar la información aportada por el museo. Ambas opciones conviven en un mismo contexto que identifica claramente la procedencia de cada tipo de catalogación.

\section{CONCLUSIONES}

La participación de los visitantes que facilita la Web 2.0 es un aspecto incómodo para los museos porque implica ceder a personas externas a la entidad cierto porcentaje del discurso institucional. A juzgar por los museos analizados, el uso mayoritario de formatos 2.0 cuenta con los visitantes sólo de forma limitada ya que reduce su participación a comentarios y valoraciones sobre contenidos museográficos cerrados, previamente desarrollados por el museo. Esta estrategia da cabida a la voz de los visitantes pero, al mismo tiempo, minimiza injerencias externas en la comunicación institucional del museo. La aportación, co-creación y re-utilización de contenidos, aunque son inherentes al espíritu de la Web 2.0, sólo aparecen verdaderamente planteadas en poco más del $2 \%$ de los museos estudiados.

\section{REFERENCIAS}

Anderson, P. (2007). What is Web 2.0? Ideas, technologies and implications for education. JISC Technology and Standards Watch. Recuperado el 22 de junio de 2011, de www.jisc.ac.uk/media/documents/techwatch/tsw0701b.pdf

Barnett, E. (2011). Social networks beat entertainment sites as most popular UK online activity. The Telegraph. Recuperado el 17 de junio de 2011, de www.telegraph.co.uk/technology/news/8385859/Social-networks-beatentertainment-sites-as-most-popular-UK-online-activity.html.

Crenn, G. \& Vidal, G. (2008). L'introduc-tion des technologies web 2.0 dans les musées d'artmoderne et contemporain: vers de nouvelles relations entre l'institution muséale et sespublics?Recuperado el 27 de junio de 2011, de www.centrepompidou.fr/musee2.0

Espadas Bardón, J. (2009). Museums Web 2.0 Ranking. Recuperado el 24 de junio de 2011, de www.museothyssen.org/blogs/museums_web_20_ranking_jun_2009.pdf.

Flatt, M. (2010). ¿Necesitan los museos a los medios de comunicación social, o más bien el boca a boca? Revista de los museos de Andalucía, 8(12): 34. 
Kelly, L. (2009). The Impact of Social Media on Museum Practice. Recuperado el 27 de junio de 2011, de australianmuseum.net.au/document/The-Impact-of-Social-Mediaon-Museum- Practice.

López, X., Margapori, I., Maragliano, R., \& Bove, G. (2010). The presence of Web 2.0 tools on museum websites: a comparative study between England, France, Spain, Italy and the USA. Museum Management And Curatorship, 25(2): 235-249.

Macarthur, M. (2007). Can museums Allow Online Users to Become Par-ticipants?

Recuperado el 01 de junio de 2011, de www.aam-

us.org/pubs/webexclusive/digitalmuseum

.cfm.

Marsh, C. (1996). The Role of Emotions. Recuperado el 13 de junio de 2011, de www.astc.org/resource/education/learning_marsh.htm.

O'reilly, T. (2005). What is Web 2.0: Design Patterns and Business Models for the Next Generation of Software. Recuperado el 29 de junio de 2011, de oreilly.com/web2/archive/what-is- web-20. html.

O'reilly, T. (2009). Web Squared: Web 2.0 Five Years On. Recuperado el 3 de junio de 2011, de www.web2summit.com/web2009/public/schedule/detail/10194.

Peacock, D. (2008). Making ways for change: Museums, disruptive technologies and organisational change. Museum Management and Curatorship, 23: 333-351.

Rodá, C. (2010). De 1.0 a 2.0: el viaje de los museos a la comunicación social. Revista de los museos de Andalucía, 8(12): 22-33.

Simon, N. (2010). The Participatory Museum. Museum 2.0. California: Santa Cruz.

Teather, L. \& Wilhelm, K. (1999). Web Musing: Evaluating Museums on the Web from Learning Theory to Methodology. Recuperado el 28 de junio de 2011, de http://www.archimuse.com/mw99/papers/teather/teather.htm.

Vogelsang, A. \& Minder B. (2011). Audience+: A Holistic Approach to Devel-oping Social Media Guidelines for Swiss Museums. Recuperado el 27 junio de 2011, de conference.archimuse.com/mw2011/papers/audience_a_holistic_approach_to_deve loping_soc.

Walsh, P. (1997). The Unassailable Voice. Recuperado el 29 de junio de 2011, de www.archimuse.com/mw97/speak/walsh.htm. 


\section{José Nicolás del Río-Castro}

Doctor en Arte por la Universidad de Santiago de Compostela, Master por la Universidad de Rutgers en EE.UU y estudios de Diseño Gráfico en la Escuela de Artes Visuales de Nueva York. A lo largo de su carrera ha compaginado su trabajo profesional como diseñador gráfico con labores docentes en el Master de Creación y Comunicación Digital de la Universidade da Coruña, en los cursos de postgrado DIME (Diseño de Materiales Interactivos para Educadores) de la Universidad de Santiago de Compostela y en el Master en Arte, Museología y Crítica Contemporáneas, de la misma universidad. También ha impartido cursos de grado y licenciatura en la facultad de Ciencias de la Comunicación de la Universidad da Coruña. 
Anexo 1

MUSEOS VISITADOS

\section{Alemania}

Kunstmuseum, Wolfsburg

Schirn Kunsthalle, Frankfurt

Austria

Kunsthalle, Viena

MUMOK, Viena

Bélgica

MAC's, Grand-Hornu

\section{Dinamarca}

ARKEN, Ishøj

KunstMuseum, Horsens

Museum for Samtidskunst, Roskilde

Nicolaj Art Center, Copenhague

España

CCCB, Barcelona kunstmuseum-wolfsburg.de schirn.de

kunsthallewien.at

mumok.at

grand-hornu.be

arken.dk

horsenskunstmuseum.dk

samtidskunst.dk

kunsthallennikolaj.dk

cccb.org 
Centro Guerrero, Granada

Guggenheim Bilbao

Fundación NMAC, Cádiz

IVAM, Valencia

Museo Reina Sofía, Madrid

Patio Herreriano, Valladolid

\section{Finlandia}

Kiasma, Helsinki

\section{Francia}

Artothéque, Caen

Centre Pompidou, París

Fondation Espace Ecureuil, Marsella

FRAC, Centre, Orleans

FRAC, Baja Normandía, Caen

FRAC, Borgoña, Dijon

FRAC, Pays de la Loire, Carquefou

FRAC, Picardie, Amiens

FRAC, Provenza-Alpes-Côte d'Azur, Marsella

Le Creux de l'Enfer, Thiers

Les Abbatoirs, Toulousse

MAC /VAL, Vitry-sur-Seine

Palais de Tokio, París

\section{Gran Bretaña}

Arnolfini, Bristol

Baltic Mill, Gateshead

Cornerhouse, Manchester

INIVA, Londres

Kettle's Yard, Cambridge

Northern Gallery Of Contemp. Art, Sunderland kiasma.fi

centroguerrero.org

guggenheim-bilbao.es

fundacionnmac.org

ivam.es

museoreinasofia.es

patioherreriano.org

artotheque-caen.net

centrepompidou.fr

caisseepargne-art-...

... contemporain. $\mathrm{fr}$

frac-centre.fr

frac-bn.org

frac-bourgogne.org

fracdespaysdelaloire.com

frac-picardie.org

fracpaca.org

creuxdelenfer.net

lesabattoirs.org

macval.fr

palaisdetokyo.com

arnolfini.org.uk

balticmill.com

cornerhouse.org

iniva.org

kettlesyard.co.uk

ngca.co.uk 
Scottish Gallery of Contemp. Art, Edimburgo

South London Gallery

Tate Modern, Londres

The Fruit Market, Edinburgo

\section{Holanda}

Stedelijk, Amsterdam

Museum voor Moderne Kunst, Arnhem

Van Abbemuseum, Eindhoven

Irlanda

IMMA, Dublín

Italia

GAMEC, Bérgamo

MAMbo, Bolonia

MART, Trento

Museo d'Arte Contemp. Villa Croce, Génova

Luxemburgo

MUDAM

\section{Suecia}

Moderna Museet, Oslo

\section{Suiza}

Elysee, Lausanne

Fondation Beyeler, basilea

FRI-ART, Friburgo

KunstMuseum, Thun

MAMCO

\section{China:}

MOCA, Taipei

\section{Corea:}

MOCA, Seúl

\section{Australia}

nationalgalleries.org southlondongallery.org tate.org.uk/modern

fruitmarket.co.uk

www.stedelijk.nl

www.mmkarnhem.nl

www.vanabbemuseum.nl

imma.ie

gamec.it

mambo-bologna.org

mart.tn.it

museovillacroce.it

mudam.lu

www.modernamuseet.se

elysee.ch

fondationbeyeler.ch

fri-art.ch

kunstmuseumthun.ch

mamco.ch

mocataipei.org.tw

moca.go.kr 
ACCA, Southbank

Griffith Artworks; South Bank

Heide Museum of Modern Art, Bulleen

Nueva Zelanda

Adam Art Gallery, Wellington

Canadá

MACM; Montreal

\section{Estados Unidos}

Albright - Knox, Búffalo

BMOCA, Boulder

California Center for the Arts, Escondido

Contemporary Art Museum, St. Louis

Guggenheim; Nueva York

Hirshhorn, Washington

ICA Boston

ICA Phila, Filadefia

MassMOCA, Massachusetts

MCA Chicago

MCASD, San Diego

MMOCA, Madison

MOCANOMI, Miami

MoMA, Nueva York

New Museum, Nueva York

Pulitzer, St. Louis

San José Museum of Art

SFMoMA, San Francisco

SMoCA, Scottsdale

The Aldrich, Ridgefield

The Contemporary, Baltimore

The Galleries at Moore University accaonline.org.au

griffith.edu.au

heide.com.au

adamartgallery.org.nz

macm.org

albrightknox.org

Adam Art Gallery

artcenter.org

camstl.org

guggenheim.org

hirshhorn.si.edu

icaboston.org

icaphila.org

massmoca.org

mcachicago.org

mcasd.org

mmoca.org

mocanomi.org

moma.org

newmuseum.org

pulitzerarts.org

wWw.sjmusart.org

sfmoma.org

smoca.org

aldrichart.org

contemporary.org

thegalleriesatmoore.org 
Walker Art Center, Minneapolis

Warhol Museum, Pittsburg

Whitney, Nueva York

México

MARCO, Monterrey

Argentina

MACRO, Rosario

\section{Brasil}

MAC Niteroi, Río de Janeiro walkerart.org

warhol.org

whitney.org

marco.org.mx

macromuseo.org.ar

macniteroi.com.br 